HUNGARIAN AGRICULTURAL ENGINEERING

$N^{\circ} 37 / 2020$ 90-96

Published online: http://hae-journals.org/

HU ISSN 0864-7410 (Print) / HU ISSN 2415-9751(Online)

DOI: 10.17676/HAE.2020.37.90

Received: 22.04.2019 - Accepted: 12.05.2020
PERIODICAL OF THE COMITTEE OF

AGRICULTURAL AND BIOSYSTEM

ENGINEERING OF

THE HUNGARIAN ACADEMY OF SCIENCES

and

SZENT ISTVÁN UNIVERSITY

Faculty of Mechanical Engineering

\title{
APPLICATION POSSIBILITIES AND BENEFITS OF IOT (INTERNET OF THINGS) IN AGRICULTURAL PRACTICE. QUO VADIS IOT?
}

Author(s):

A.Nyéki, M. Neményi, G. Teschner, G. Milics, A. J. Kovács

\section{Affiliation:}

Department of Biosystem and Food Engineering, Faculty of Agricultural and Food Sciences, Széchenyi István University, Vár tér 2., Mosonmagyaróvár, H-9200, Hungary

\section{Email address:}

nemenyi.miklos@sze.hu,nyeki.aniko@sze.hu

Motto: "Using gadgets is not a goal but a tool"

Abstract: Nowadays we are not able to exploit the technical and IT advantages provided by precision technologies from an ecological or economic point of view.

More than 20 years of experience unfortunately proves that we do not have adequate applied biological knowledge.

Today, our technical and IT knowledge provides us with many opportunities, e.g., during sowing we can change the distance between seeds, therefore altering the density of plants, or even switching to another variety. We can collect a lot of data during sowing but we can also take into account previous experience with the soil. The problem is that the relationship between the known data and the optimal number (density) of plants is still not yet known satisfactorily.

In this article we present the opportunities that IoT offers, primarily in terms of sustainable agriculture. The worldwide spread of IoT can also be considered the 3rd green revolution

Keywords: internet of things (IoT), sensor networks, big data, automating data collection, artificial intelligence

\section{Introduction, chronology of technological development in plant production}

\section{The first Green Revolution}

In the early years of the 1940s, Norman Borlaug's name became associated with the Green Revolution. It was the first technology-level production system using state-of-the-art wheat genotypes, chemicals, and technical background. The result was that in only a few years Mexico became self-supporting in cereal grain despite a drastic increase in population, despite previously needing to rely on significant imports. This program was also successful in Pakistan and India.

\section{The second Green Revolution}

Among the first in Europe, research activities started in 1998 in Mosonmagyaróvár (Hungary) with grain yield mapping. Additionally, the project included data collection, sensor techniques and sampling methods needed for precision agriculture (site-specific plant production activities). These were complemented with remote sensing: the evaluation of UAV (unmanned aerial vehicles or drones) and satellite imaging techniques. The results obtained also contributed to the examination of climate change effects on yield with the development of decision support models (e.g., DSSAT). [10]

The formal official definition of precision farming by the Board of International Society for Precision Agriculture (ISPA) is: "Precision Agriculture is a management strategy that gathers, processes and analyses temporal, spatial and individual data and combines it with other information to support management decisions according to estimated variability for improved resource use efficiency, productivity, quality, profitability and 
sustainability of agricultural production" [1]. In the field of animal husbandry, this definition can be supplemented by the following: Precision animal husbandry is intelligent farming that can improve, or at least objectively document, animal welfare on farms [2].

The initial results of the PA (Precision Agriculture) research group in Mosonmagyaróvár were reported in 2003 in the scientific journal Computers and Electronics in Agriculture. This study was for a long time one of the most cited articles in the journal and it is still regularly cited today [3].

The world has also changed in this area. David Tilman has drawn attention, as early as 1998, to the need for greening the Green Revolution, i.e., to take sustainability into account [4]. He also indicated that precision agriculture could be the solution and suggested that our knowledge of soil biology should be expanded. In 2002 Tilman shared startling data with his colleagues. In that data, it should be emphasized that only $30-50 \%$ of nitrogen fertilizers and $45 \%$ of phosphorus fertilizers are used by crops [5]. Following the chronology of events, in 2006 a Ph.D. dissertation was written at the Department of Biological Systems and Food Technology, University of West-Hungary (today: Széchenyi István University) in which artificial intelligence (AI) and neural networks were applied to the size definition of management zones [6]. We have achieved remarkable additional results in several respects including: soil resistance mapping [7], the specification of the continuous crop moisture measurement in the combine thresher [8], and ECa mapping [9]. We have achieved significant results in the development of the above-mentioned plant physiological models, specifically and primarily DSSAT $[10,11,12]$. Despite the effort in scientific activities around the world, it seems that precision technologies have not fully lived up to their promise. This finding applies in particular to sustainability criteria, environmental and nature protection.

After 16 years the alarm bells published by Tilman et al. (2002) [5], at the International "Precision Conference", Longchamps et al. (2018) [13] - along with N. Tremblay, then president of ISPA - indicated that adverse ecological challenges and the time distance between the answers to it is constantly increasing. From this, a legitimate conclusion was drawn that a paradigm shift is needed, which means increasing databases by many orders of magnitude. We need to consider Albert Einstein's idea: "The significant problems we face cannot be solved at the same level of thinking we were at when we created them."

Authors, with more than two decades of research experience, are showing that we need to go further, and the IoT (Internet of Things) provides an opportunity to do so.

\section{The third Green Revolution}

\section{Definitions of IoT}

The definition of the Internet of Things has not yet been clarified in the same way as precision agriculture.

The IoT can also be considered the fifth industrial revolution, as it first brought a fundamental change to large industrial companies in the monitoring of the production chain, in quality assurance. It can also be called a revolution in that it completely changes our living conditions. Not only will it be possible to explore contexts for which the appropriate database and modelling methods have not been suitable so far, but also because the system can predict changes, not only climate change. Society can prepare for that change. IoT is a global system of computer networks. "Everything connected to everything" means that living and inanimate "objects" come into contact with each other, the possibility of technical-IT interaction of which has not been given so far. Information about individuals is provided by sensors. These sensors are programmable, can analyse the signal, and both detect and transmit this information (edge and fog computing).

In summary: "The Internet of Things is a technological revolution that represents the future of computing and communications, and its development depends on dynamic technical and IT innovation in a number of important fields, from wireless sensors to nanotechnology" [14]. In a small environment scenario, "An IoT is a network that connects uniquely identifiable "Things" to the Internet. The "Things" have sensing/actuator and potential programmability capabilities. Through the exploitation of unique identification and sensing, information about the "Thinge" can be collected and the state of the "Thinge" can be changed from anywhere anytime, by anything" [15]. 


\section{What is IoT}

In the case of IoT technologies (fig. 1), the data transmission takes place using a network in such a way that human-human, human-computer interaction will not be necessary, instead, in the future the M2M (machine to machine) connection system will be realized. In the future, IoT will connect millions of devices with different technical features, which differ in terms of their technical characteristics (power supply, environmental adaptability, compatibility with other devices, etc.).

The evolution of IoT is increasingly taking the development of the network in that direction and revolutionizing the way it processes information from different locations with a unified approach to inform decision-making.

Big Data can only be processed with the help of artificial intelligence (AI).

It is important to note that while traditionally, e.g., in plant physiology models, the number of independent variables is limited, in AI it is theoretically possible to process infinite data if the computer capacity allows it. AI data mining "draws attention" to the most important factors influencing dependent variables, e.g., yield (weeds, pests, the appearance of pathogens, groundwater nitration, etc.).

From an agricultural technical point of view, it is important to note that the machine manufacturers, currently only actuators and self-propelled machine manufacturers, are placing more and more online sensors in their equipment with which they are in constant contact and obtain data from (continuous power measurement, engine diagnostics, etc.). This trend also contributes to the revolution of machine design, as operating conditions do not need to be modelled and direct information can be obtained from them. [16].

\section{Architecture of IoT}

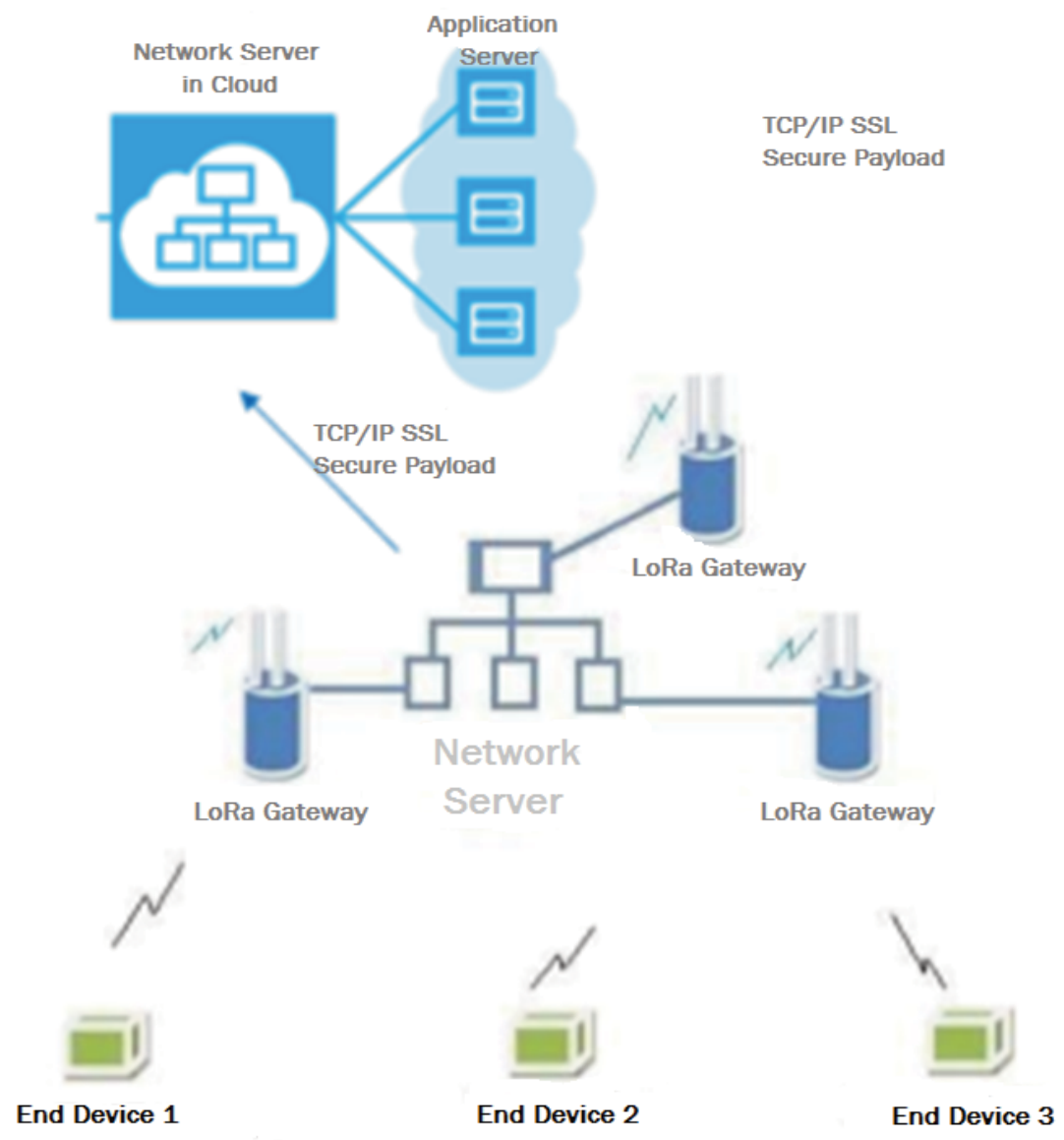

Figure 1. Architecture of LoRaWAN system 
In agriculture, the most important requirements for IoT systems are having a range of 10-15 km and low energy consumption of data transmission devices. Currently, the LoRa system is the most suitable for this. LoRa (Long Range) is a wireless communication technology, which has two parts: LoRa (Long Range; the physical layer enabling more than $10 \mathrm{~km}$ transmission in rural areas, with a low power consumption); and LoRaWAN, which is the communication layer of system.

General structure of IoTs:

I. End nodes: 1. Sensors; 2. LoRa Transponders that transmit signals with radio transmission methods; 3. Microcontroller (optional), which is programmable by Phyton or Java.

II. LoRa Gateways are connected to the Internet through IP protocols and transmit data from sensors to a network, server or cloud.

III. Network: WSN (Wireless Sensor Network). It can be a cloud-based platform like TTN (The Thinks Network), or LoRa IoT.

IV. Application Servers

New Opportunity, the NB-IoT

"LoRa are non-cellular, NB-IoT are cellular IoT communication systems (NB-IoT: Narrow Band IoT).

Ranges of both LoRa and NB-IoT are 10-15 km. NB-IoT devices rely on 4G-5G coverage, so they are able work well indoors and in crowded urban areas.

LoRa devices work well when they are in motion, e.g., data collection with robots, tracking of shipments, etc.

Since LoRaWAN does not rely on cellular data or wifi for operation, its coverage remains relatively steady across all types of locations." Details can be found in [17].

\section{Potential applications, Agricultural IoT in Mosonmagyaróvár: M-AIoT}

This study mainly presents the objectives and the framework of our Agro-IoT system. Precision plant production is based on management zone delineation. A decision support model, such as DSSAT, requires more than 50 input parameters per management zone (out of them 22 data from the soil). To enhance the accuracy of the description of physiological characteristics of plants the amount of measured data has to be increased further. The Agro-IoT (Mosonmagyaróvár) system's main purpose is to collect data from crop fields and from the surrounding natural (or quasi-natural) areas. Thereby, the relationship between natural ecology and agro-ecology can be profoundly studied. One of the tools of processing Big Data is using artificial intelligence. The long-term aim is the continuous automatic validation of data provided by the on-the-go measuring systems that occurs while passing by the installed stations and making wireless corrections in the measurement of mobile devices. Based on previous experience collected by research, the IoT system will be expanded and operated.

In the first stage of our "Agro-IoT" project the aims are to compile soil and micro-climatic information and their effects in site-specific crop production. First of all maize and winter wheat cultivation needs to tested, in order to utilize Big Data that later will support the decision system for farmers. The core part of this activity is automating data collection, extending remotely obtained parameters of crops, and accessing real-time data from any device at any time. The real challenge is the fusion of data gathering from different platforms. The installed sensors (fig. 2) are measuring parameter samplings every 16 minutes. The monitoring parameters are soil electrical conductivity, soil water content and soil temperature at different depths $(5,20,40,60$ and $80 \mathrm{~cm}$ ), air temperature, humidity and pressure, and leaf surface humidity.

Other devices detect the environmental factors, such as ground water $\mathrm{pH}$ and nitrite-nitrate content, soil $\mathrm{CO}_{2}$ and ammonium emission. A complex meteorological station will analyse ten parameters from the crop microclimate.

The information, automatically gathered by the sensors, is analysed using a traditional method and these are compared with different computations (e.g., artificial intelligence). Until now, parameters were measured manually in a difficult, long and expensive process.

This new sensor network hopefully offers useful "Big Data" results. As our measurements and findings will grow, we hope to get closer the final aims of the project namely a fully automated sustainable crop production systems based on proper Big Data evaluations. 


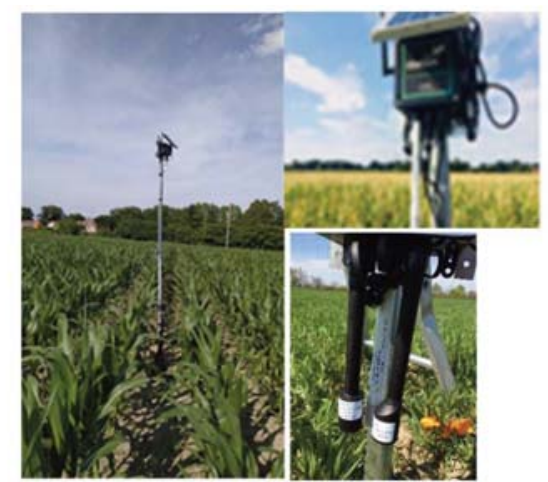

air temperature, humidity, pressure, $\mathrm{CO}_{2}$ and ammonia

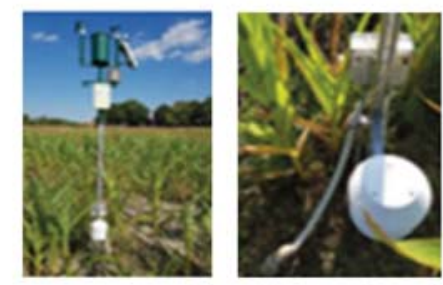

air temperature, humidity, wind speed, precipitation and global radiation

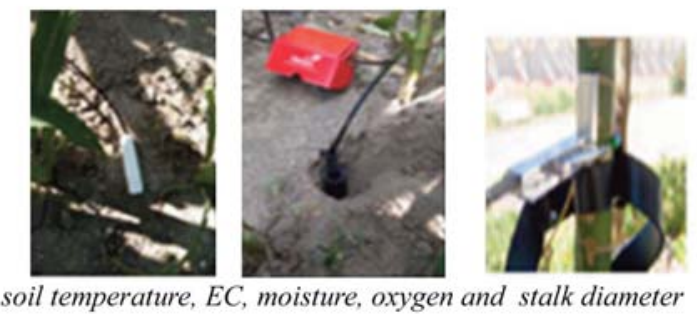

Figure 2. Installed sensors in a research crop field (Mosonmagyaróvár, 2019)

\section{Conclusion}

The reason for IoT progress is that the amount of data in precision Agriculture is increasing significantly. The system that will be built in agriculture will be able to collect data on the soil, plants, and their environment using long-range wireless transmission. The installed systems, the on-the-go (mobile), the UAV (Unmanned Aerial Vehicle), and satellite sensors can provide long-range data transmissions with low energy consumption. Big Data meets the needs of data processing with artificial intelligence methods. The purpose of all this is to serve the precision, site-specific crop production, in order to accomplish more accurate forecasts with sustainable approach.

The complete system prepares application plans and designs precision work operations based on fieldspecific sensors and information obtained by IOT system. Some elements have already been realised for this, e.g., modification of robot detectors in order to be capable of colour recognition. The data collected from the sensors are stored on an online site. In addition, the installed IoT stations continuously measure the incoming data, if necessary, they calibrate the data provided by robots or other platforms. At the same time, the processing of data in a unified system (data fusion) should be mentioned as a challenge in which IOT systems and artificial intelligence will play a role. Filtering out the right information from the data and using it in production is still not possible. Wireless data transmission methods will facilitate the development of a unified data structure in farming as well; these solutions will require less manual data collection and will be available to the farmer at any time. At the same time, the M2M unmanned system is becoming more and more realized

In animal husbandry, in addition to real-time automatic monitoring of production parameters, animal health and welfare, and environmental impacts, these systems also support farm management decision-making, which results in cost reductions. We achieve fewer negative environmental impacts with increased productivity and 
product quality. In cattle breeding, for example, IoT solutions are able to detect the microclimate change. This includes the detection of heat stress and the negative effects it causes, such as reduced feed intake, unfavourable pregnancy rates, and so on. They can also provide a solution to the needed intervention [2].

Practical applications and research are not always in line. Farmers are not always able to apply and adapt all results. Technical IT solutions have exceeded agronomic knowledge. There are all opportunities to harmonize the aims of technical-IT and applied biology (agronomy) research.

\section{Acknowledgements}

The project is financed by the "Thematic Area Excellence Program" of the National Research, Development and Innovation Office (TUDFO/51757/2019-ITM). The research was partly supported by the European Union and the Hungarian Government from the project 'FIEK - Center for cooperation between higher education and the industries at Széchenyi István University under grant number GINOP-2.3.4-15-2016-00003.

\section{References}

[1] https://www.ispag.org/about/definition

[2] Banhazi, T.M., Lehr, H., Black, J.L., Crabtree, H., Schofield, P., Tscharke, M., Berckmans, D.: 2012. Precision Livestock Farming: An international review of scientific and commercial aspects. Int. J. Agric \& Biol Eng. Vol. 5. No. 3. https://core.ac.uk/download/pdf/11049514.pdf

[3] Neményi, M., Mesterházi, P. Á., Pecze, Zs., Stépán, Zs.: 2003. The role of GIS and GPS in precision farming. Comput. Electron. Agr. Vol. 40 (1- 3), pp. 45-55. http://dx.doi.org/10.1016/S01681699(03)00010-3

[4] Tilman, D.: 1998. The greening of the green revolution. Nature Vol. 396. pp. 211-212 http://dx.doi.org/ $10.1038 / 24254$

[5] Tilman, D., Cassman, K. G., Matson, P. A., Naylor, R., Polasky, S.: 2002. Agricultural sustainability and intensive production practices. Nature Vol. 418 pp. 671-677. http://dx.doi.org/ 10.1038/nature01014

[6] Mike-Hegedús, F.: 2004. Applying fuzzy logic and neural networks to database evaluation in precision agriculture. PhD Thesis. University of West-Hungary, Mosonmagyaróvár. (In Hungarian).

[7] Neményi, M., Mesterházi, P. Á., Milics, G.: 2006. An Application of Tillage Force Mapping as a Cropping Management Tool. Biosyst. Eng. Vol. 94 (3), pp. 351-357.

http://dx.doi.org/10.1016/j.biosystemseng.2006.04.005

[8] Csiba, M., Kovács, A.J., Virág, I., Neményi, M.: 2013. The most common errors of capacitance grain moisture sensors- effect of volume change during harvest. Precision Agric. Vol. 14, pp. 215-223. http://dx.doi.org/10.1007/s11119-012-9289-y

[9] Nagy, V., Milics, G., Smuk, N., Kovács, A.J., Balla, I., Jolánkai, M., Deákvári, J., Szalay, K., Fenyvesi, L., Štekauerová, V., Wilhelm, Z., Rajkai, K., Németh, T., Neményi, M.: 2013. Continuous field soil moisture content mapping by means of apparent electrical conductivity (ECa) measurement. J. Hydrol. Hydromec. Vol. 61 No. 4, pp. 305-312. https://doi.org/10.2478/johh-2013-0039

[10] Nyéki A. 2016: Relationship between precision crop production and sustainable agriculture. PHD THESIS. Szechenyi Isvan University, Mosonmagarovar. (IN HUNGARIAN)

[11] Nyéki, A., Milics, G., Kovács, A.J., Neményi, M.: 2013. Improving yield advisory models for precision agriculture with special regards to soil compaction in maize production. Precision Agriculture'13 (Editor: J. V. Stafford). pp. 443-448. https://doi.org/10.3920/978-90-8686-778-3

[12] Nyéki, A., Milics, G., Kovács, A.J., Neményi, M.: 2017. Effects of soil compaction on cereal yield: review. Cereal Research Communications. Vol. 45. No. 1. pp. 1-22. https://doi.org/10.1556/0806.44.2016.056

[13] Longchamps, L., Tremblay, N., Panneton, B.: 2018. Observational studies in agriculture: paradigm shift required Proceedings of the14th International Conference on Precision Agriculture. June 24 - June 27, 2018 Montreal, Canada 
[15] Madakam, S., Ramaswamy, R., Tripathi, S.: 2015. Internet of Things (IoT): A literature review. IT Applications Group, National Institute of Industrial Engineering. Vol. 3. pp.164-173.

https://doi.org/10.4236/jcc.2015.35021

[16] Stočes, M., Vaněk, J. Masner, J. Pavlík, J.: 2016. Internet of Things (IoT) in agriculture - Selected Aspects. Sciences Prague. Vol. 8. No. 1. https://doi.org/10.7160/aol.2016.080108

[17] Ram, P. (2018): LPWAN, LoRa, LoRaWAN and the Internet of Things. PART I - Understanding the LPWAN, LoRa and LoRaWAN technology. Medium.Com, Aug.7. 